\title{
GESTAÇÃO OBTIDA EM COELHA APÓS OOFORECTOMIA BILATERAL E TRANSPLANTE OVARIANO HOMÓGENO
}

\author{
PREGNANCY IN RABBITS AFTER BILATERAL OOPHORECTOMY AND \\ ALLOGENIC OVARY TRANSPLANTATION
}

\author{
Andy Petroianu , TCBC-MG ${ }^{1}$ \\ Leonardo de Souza Vasconcellos ${ }^{2}$ \\ Juliana Moysés Leite ${ }^{3}$ \\ Luiz Ronaldo Alberti ${ }^{4}$ \\ Lúcia Porto Fonseca de Castro ${ }^{5}$
}

\begin{abstract}
RESUMO: Objetivo: Verificar a possibilidade de fertilização natural após ooforectomia total bilateral e transplante ovariano homógeno ortotópico sem anastomose vascular e imunossuprimidos pela ciclosporina. Método: Foram utilizadas dez coelhas da raça Nova Zelândia Branca e Califórnia. Realizou-se ooforectomia total bilateral e transplante ortotópico dos ovários entre pares de animais. De um lado, foi transplantado o ovário íntegro e de outro, o ovário fatiado. Não houve anastomose vascular. A imunossupressão se deu com a administração ciclosporina através de tubo orogástrico diariamente, durante seis meses. Três meses depois, as fêmeas foram colocadas diariamente para copular com machos sabidamente férteis da raça Nova Zelândia Branca, por outros seis meses. No final do período do experimento, foram realizadas dosagens de estradiol, progesterona, hormônio folículo estimulante e hormônio luteinizante, além de estudo histológico dos ovários, tubas e úteros. Resultados: Gravidezes ocorreram em cinco coelhas, sendo que, em quatro delas, houve nascimento de filhotes. As dosagens hormonais estiveram dentro da faixa de normalidade em todos os animais. Os ovários transplantados estavam rodeados de tecido conjuntivos, bem vascularizados e com folículos ovarianos em vários estádios de desenvolvimento. Conclusões: Obteve-se, com sucesso, a fertilização natural e manutenção hormonal feminina em coelhas submetidas a transplante homógeno de tecido ovariano sem anastomose vascular e imunossuprimidos pela ciclosporina.
\end{abstract}

Descritores: Ovário; Transplante; Ovariectomia; Gravidez; Coelhos; Ciclosporina; Fertilização.

\section{INTRODUÇÃO}

Estudos experimentais utilizando tecidos ovarianos criopreservados comprovaram a eficácia dos transplantes ovarianos heterotópicos como alternativa mais fisiológica de manter a função hormonal em mulheres que precisam se submeter à retirada de ovários normais, mostrando inclusive desenvolvimento e viabilidade dos folículos ovarianos ${ }^{1-7}$. Entretanto, pouca atenção se deu à manutenção da fertilidade após os transplantes. A maioria dos estudos sobre preservação de tecido ovariano restringiu-se aos transplan-

1. Professor Titular do Departamento de Cirurgia da Faculdade de Medicina - UFMG; Docente Livre da Faculdade de Medicina de Ribeirão Preto - USP; Docente Livre da Escola Paulista de Medicina - UNIFESP; Doutor em Fisiologia e Farmacologia; Pesquisador IA do CNPq.

2. Residente de Patologia Clínica do Hospital das Clínicas da UFMG.

3. Residente de Ginecologia e Obstetrícia do Hospital Mater Dei.

4. Residente de Cirurgia Geral do Hospital Júlia Kubitschek.

5. Professora do Departamento de Anatomia Patológica da Faculdade de Medicina da UFMG; Mestre em Patologia Geral, UFMG.

Recebido em 22/01/2002

Aceito para publicação em 30/04/2002

Trabalho realizado no Departamento de Cirurgia, Faculdade de Medicina da UFMG, com auxílio do CNPq e da FAPEMIG. 
tes autógenos. Transplantes ortotópicos ou heterotópicos de ovários homógenos foram pouco investigados até o momento. Citam-se apenas alguns estudos em camundongos, ratos e cobaias com restabelecimento apenas parcial da fertilidade. As gravidezes obtidas nesses estudos ocorreram apenas quando se realizava o transplante em indivíduos geneticamente semelhantes. Além disso, a imunossupressão era obtida por irradiação corporal total ou localizada na região dorsolombar, que é freqüentemente seguida por complicações diversas, principalmente infecções fatais ${ }^{7}$.

A ciclosporina A (CyA) é um peptídeo derivado de fungos, usada no tratamento de pacientes submetidos a transplantes de órgãos. Sua atividade imunossupressora baseia-se na inibição da resposta imune celular, assim como na diminuição da produção de linfócitos $\mathrm{T}$ dependentes de anticorpos ${ }^{8}$. Há trabalhos que sugerem disfunções do sistema endócrino decorrentes dos efeitos secundários da $\mathrm{CyA}{ }^{9}$. Foram descritas alterações da função gonadal em ratos e humanos ${ }^{10,11}$, provavelmente devido à interação entre a CyA e a prolactina sobre o mesmo receptor linfocítico, além de diminuição da fertilidade e alterações no desenvolvimento fetal ${ }^{8}$.

O objetivo do presente trabalho foi avaliar a possibilidade de fertilização natural após ooforectomia total bilateral e transplante homógeno de ovário em posição ortotópica, sem anastomose vascular, na presença de imunossupressão com ciclosporina.

\section{MÉTODO}

Esta pesquisa experimental foi realizada de acordo com as recomendações das Normas Internacionais de Proteção aos Animais ${ }^{12,13}$, tendo sido aprovada por Comissão de Ética em Pesquisa da Universidade Federal de Minas Gerais.

Foram estudadas 10 coelhas (Oryctogalus cuniculus) das raças Nova Zelândia Branca $(\mathrm{n}=5)$ e Califórnia $(n=5)$ e cinco machos sabidamente férteis da raça Nova Zelândia Branca. Os animais provenientes do Biotério Central da Escola de Veterinária da Universidade Federal de Minas Gerais (UFMG), foram mantidos em gaiolas individuais, onde receberam ração para coelhos e água à vontade. Os animais permaneceram em adaptação e observação do estado de saúde por 20 dias. Todos os procedimentos foram feitos nas dependências do Laboratório de Cirurgia Experimental do Departamento de Cirurgia da Facul- dade de Medicina da UFMG, obedecendo às normas técnicas de assepsia e anti-sepsia.

No início do experimento, todos os animais estavam sexualmente maduros e com peso variando de 2400 a 2700 gramas. No pré-operatório, os animais foram mantidos em jejum de 12 horas. Uma hora antes do procedimento cirúrgico, os coelhos foram pesados e receberam ciclosporina em solução na dose de $10 \mathrm{mg} / \mathrm{kg}$, além de $50 \mathrm{mg} / \mathrm{kg}$ de cefadroxila (antibioticoprofilaxia). Ambas as substâncias foram dissolvidas em $10 \mathrm{ml}$ de leite e administradas através de um cateter orogástrico de 12 Fr. A anestesia foi induzida com injeção intramuscular de cloridrato de quetamina, na dose de $50 \mathrm{mg} / \mathrm{kg}$.

Um par de coelhas - uma Califórnia e outra Nova Zelândia Branca foram operadas simultaneamente. Através de laparotomia mediana, realizava-se ooforectomia total bilateral, preservando a integridade tubária. Ambos os ovários de cada coelha foram retirados e um deles foi fatiado transversalmente em três segmentos. Em seguida, os ovários de uma coelha foram transplantados ortotopicamente na outra coelha e vice-versa. Em um lado, transplantou-se o ovário íntegro e do outro lado, o ovário fatiado. Todos os implantes ovarianos foram feitos sem reconstituição vascular e fixados com apenas um ponto de náilon 5-0.

$\mathrm{O}$ útero e as trompas permaneceram íntegros em todos os animais. A cavidade abdominal foi fechada em dois planos com sutura contínua de náilon 3-0. Após o ato cirúrgico, e durante todo o período de acompanhamento, as coelhas receberam água e ração ad libitum.

Durante os três primeiros dias pós-operatórios, os animais receberam antibioticoprofilaxia com cefadroxila na dose de $50 \mathrm{mg} / \mathrm{kg}$ dissolvida em $10 \mathrm{ml}$ de leite, através de cateter orogástrico.

As coelhas receberam diariamente, durante seis meses, $10 \mathrm{mg} / \mathrm{kg}$ de ciclosporina dissolvidas em $10 \mathrm{ml}$ de leite através de cateter orogástrico de $12 \mathrm{Fr}$. Os animais foram semanalmente pesados para se ajustar a dose da ciclosporina.

Três meses após a cirurgia, as fêmeas foram colocadas diariamente com um macho diferente para copularem, durante outros seis meses.

No sexto mês após o transplante, foram colhidas amostras sangüíneas para dosagens de estradiol, progesterona, hormônio folículo estimulante e hormônio luteinizante. Para a obtenção dos valores de referência, foram dosados os mesmos hormônios em quatro coelhas sabidamente férteis, sadias e não operadas, 
todas de idade semelhante às coelhas submetidas ao transplante homógeno, e que constituíram o Grupo controle para a dosagem dos hormônios.

No final do período de acompanhamento, todas as coelhas foram mortas com dose inalatória letal de éter. Através de uma laparotomia mediana, a cavidade abdominal e seus órgãos foram cuidadosamente estudados. Retiraram-se o útero, os ovários e as tubas uterinas. Após a fixação dos fragmentos em solução de Bouin, eles foram processados para histologia. Secções de $5 \mu \mathrm{m}$ de espessura foram montadas em lâmina e coradas com hematoxilina e eosina.

Os resultados foram comparados por meio do teste qui-quadrado com correção de Yates para amostras pequenas. As diferenças foram consideradas significativas para valores correspondentes a $\mathrm{P}<0,05$.

\section{RESULTADO}

Todos os animais recuperaram-se das cirurgias com exceção de uma coelha Nova Zelândia Branca que morreu no final da operação, sem conseguirmos identificar a causa de sua morte. As outras coelhas apresentaram recuperação cirúrgica sem intercorrências durante os nove meses do experimento.

Gravidezes ocorreram em cinco animais, mas apenas quatro coelhas, duas Nova Zelândia Branca e duas Califórnia levaram sua gestação a termo. $\mathrm{O}$ útero de uma das coelhas Nova Zelândia Branca que foi morta no sexto mês pós-operatório, conforme o protocolo deste trabalho, continha dois fetos em seu interior. Uma coelha Califórnia teve três filhotes no sexto mês pós-operatório; uma Califórnia e outra Nova Zelândia Branca tiveram um filhote, dois meses após serem colocadas para copular; e uma outra coelha Nova Zelândia Branca teve dois filhotes, no quarto mês após o início da cópula. Não houve diferença entre o início da cópula e o nascimento dos filhotes entre as duas raças estudadas $(\mathrm{P}>0,05)$.

A Tabela 1 mostra os valores hormonais obtidos ao final do experimento. Observa-se a presença de hormônios ovarianos em dosagem adequada mesmo nas coelhas que não evidenciaram gravidez.

À segunda laparotomia, a cavidade abdominal apresentou-se com aspecto normal. $\mathrm{O}$ exame macroscópico dos órgãos reprodutores femininos mostrou ovários e tubas preservados e ausência de fibrose ou reações aparentes ao fio cirúrgico em todas as coelhas que engravidaram. Por outro lado, as coelhas que não engravidaram tiveram diversas alterações tubo-ovarianas. Em uma coelha, a tuba estava edemaciada e com sinais flogísticos locais, ovário diminuído de tamanho, bem como aderências entre o local de implantação do ovário e as tubas uterinas. As outras três coelhas também desenvolveram aderên-

Tabela 1 - Valores hormonais dosados em coelhas submetidas ao transplante ovariano homógeno ortotópico e em grupo controle.

\begin{tabular}{crccc}
\hline Coelha & Estradiol pg/ml & Progesterona pg/ml & FSH UI/ & LH UI/ \\
\hline Controle & $\mathbf{2 . 8 0 0}$ & $\mathbf{1 0 6 . 0 0 0}$ & $\mathbf{0 , 2}$ & $\mathbf{0 , 1}$ \\
1 & 10.900 & 105.000 & 0,1 & 0,3 \\
2 & - & - & - & - \\
3 & 14.600 & 90.300 & 0,2 & 0,1 \\
4 & 12.200 & 99.000 & 0,9 & 0,3 \\
5 & 733 & 91.000 & 2,7 & 0,1 \\
6 & 11.100 & 105.000 & 2,2 & 0,1 \\
7 & 11.100 & 108.000 & 1,0 & 0,2 \\
8 & 837 & 29.500 & 0,2 & 0,1 \\
9 & 4.090 & 37.700 & 1,2 & 0,1 \\
\hline
\end{tabular}

Controle - média obtida de exames em 4 coelhas adultas e férteis não submetidas a procedimento experimental.

O sangue da coelha 2 hemolisou.

FSH - hormônio folículo-estimulante

LH - hormônio luteinizante 


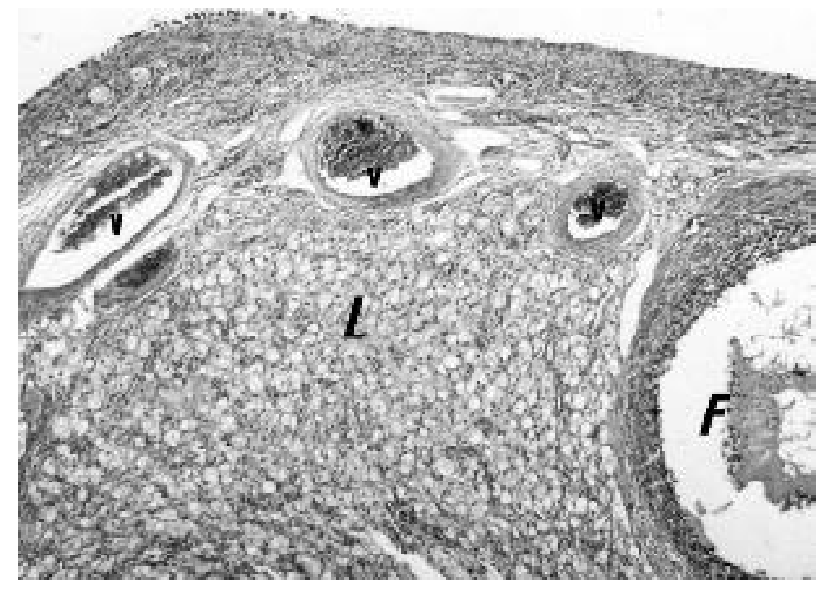

Figura 1 - Histoarquitetura do transplante homógeno ortotópico do ovário na forma íntegra, revelando aspecto histológico normal, com rica vascularização (V), ausência de infiltrado inflamatório e sinais de necrose e degeneração Observar luteinização $(L)$ e folículo $(F)$ de aspectos habituais. Hematoxilina e eosina (100X).

cias entre a tuba e o ovário, assim como entre ovário, omento e alças intestinais adjacentes. O útero em todas as coelhas apresentou aspecto normal exceto na coelha que estava grávida, na qual se encontrou útero aumentado. Não houve alterações macroscópicas em fígado, baço e intestino, exceto pelas aderências já descritas.

Os estudos histológicos dos órgãos reprodutores mostraram ovários com histoarquitetura preservada e aspecto normal (Figura 1). Não foram encontradas diferenças entre os ovários implantados íntegros ou fatiados. A viabilidade ovariana foi confirmada pela presença de angiogênese satisfatória, numerosos folículos em diferentes estádios de maturação, bem como corpos lúteos e cistos foliculares de tamanhos variáveis. Não foram identificados sinais de isquemia ou necrose. Apenas em uma nulípara identificou-se hemorragia multifocal junto à cápsula e calcificação subcapsular em um dos ovários. O útero de todas as coelhas mostrou histoarquitetura preservada.

À avaliação histológica, as tubas das coelhas que tiveram filhotes tiveram aspecto normal, com microvilosidades bem desenvolvidas, trofismo preservado e ausência de sinais inflamatórios ou degenerativos. Encontrou-se nas coelhas que não engravidaram focos de infiltrado mononuclear na mesossalpinge e hipotrofia tubária, além de reação do tipo corpo estranho no mesossalpinge, salpingite crônica discreta e hidrossalpinge. Todas as demais coelhas apresentavam histologia sem alterações.

\section{DISCUSSÃO}

Ovários já haviam sido transplantados, com relativo sucesso em pequenos roedores, porém sem índices satisfatórios de fertilidade e de restabelecimento de função ovulatória ${ }^{8,14-17}$. No presente trabalho, o transplante ovariano ortotópico avascular foi tecnicamente fácil de ser realizado e mostrou-se um bom método para completa restauração de função ovariana, tanto sob aspecto hormonal (Tabela 1), quanto reprodutivo, já que a maioria das coelhas engravidou. Além disso, é possível que outras gravidezes tenham ocorrido e não tivessem sido detectadas. Entretanto, não foram verificados abortamentos ou outras anormalidades gestacionais. Mesmo assim, o índice de gestações documentadas neste trabalho foi maior do que o registrado na literatura, em estudos que utilizaram métodos artificiais de auto-implante de gametas e embriões ou diferentes tratamentos de infertilidade ${ }^{17-20}$.

A ausência de gravidez em parte das coelhas pode ser parcialmente explicada pelos achados macroscópicos e histológicos, que indicaram processos inflamatórios em vários estádios e aderências tuboovarianas aos tecidos e órgãos adjacentes, atrofia tubária, bem como cistos hemorrágicos e mesossalpingite. Contudo, embora não tenha sido evidenciada gravidez, a função endócrina dos ovários ocorreu em todos os animais, confirmando a viabilidade e recuperação funcional ovariana.

Mediante a normalidade dos padrões histológico e funcional dos ovários reimplantados, percebe-se que o transplante ovariano sem anastomose vascular não interferiu na viabilidade dos ovários, pois todos apresentavam suprimento sangüíneo proveniente da neoformação vascular e não foi constatado sinal de isquemia ovariana. Esses achados contradizem alguns autores que consideram fundamental a revascularização em enxertos ovarianos para que eles funcionem ${ }^{21-23}$. A intensa neovascularização do ovário parece ser um dos principais fatores responsáveis para a sua sobrevida ${ }^{14}$. A angiogênese estimulada pelo próprio ovário por meio de rápida migração de células endoteliais e restabelecimento da circulação sangüínea já é conhecida na literatura ${ }^{14,24}$.

A administração diária de ciclosporina foi efetiva na prevenção de rejeição ao ovário transplantado durante todo o período do experimento. Não houve evidências histológicas ou funcionais de que a ciclosporina tivesse alterado a formação folicular ou 
a ovulação. Ainda que alguns autores tenham mostrado que a concentração mínima de ciclosporina para prevenir a rejeição tenha que ser maior que $15 \mathrm{mg} / \mathrm{kg} /$ dia ${ }^{8,25}$, a dose de $10 \mathrm{mg} / \mathrm{kg} /$ dia utilizada no presente trabalho foi suficiente para a manutenção ovariana, sem os possíveis inconvenientes de altas doses de imunossupressores.

Previamente, em estudo piloto deste trabalho, havíamos constatado que, após a suspensão de ciclosporina os ovários homógenos transplantados sobrevivem por mais três semanas, porém sua função é rapidamente deteriorada. Na quarta semana, os ovários deterioram-se completamente e desaparecem, provavelmente destruídos pelo sistema mononuclear fagocitário. Esse achado também contradiz uma pesquisa da literatura que registrou a sobrevida de ovários homógenos por várias semanas após a administração de apenas 17 dias de ciclosporina ${ }^{15}$.

Os resultados do presente estudo mostram que, em coelhas o transplante homógeno de ovário é exeqüível e restabelece a fertilidade do animal. Tal fato pode ser útil em futuras investigações relacionadas às funções endócrinas do ovário e fertilidade feminina.

Concluindo, foi registrada, com sucesso, fertilização natural em coelha submetida a transplante ortotópico de ovários homógenos, de raças diferentes. Esses ovários também preservaram sua função endócrina em nível normal. A ciclosporina foi eficaz em manter a vitalidade e função dos ovários durante todo o período de estudo. Não houve inibição da fertilidade em presença de ciclosporina.

\section{AGRADECIMENTOS}

Agradecemos ao laboratório Natures PlusSigma Pharma, São Paulo, Brasil e Novartis, São Paulo, Brasil que gentilmente forneceram a ciclosporina para o presente estudo. Agradecemos também ao CNPq e FAPEMIG pelos auxílios financeiros que permitiram a realização deste trabalho.

\begin{abstract}
Objective: To verify the fertility of rabbits submitted to allogenic ovarian transplantation without vascular pedicle and immunosupressed by cyclosporine. Methods: Ten New Zealand White and California female rabbits were submitted to ovaries exchanging between pairs of animals. In one side the ovary was intact and in the other side the ovary was sliced. Cyclosporine was administered through a 12 Frorogastric tube, every day during six months. Three months later, the animals were daily paired with sexually mature New Zealand White males during other six months. At the end of the follow-up period, blood samples were withdrawn for estradiol, progesterone, follicle stimulating hormone and luteinizing hormone assessment. Then, all animals were killed. Hystological studies of uterus, ovaries and tubes were carried out. Results: Pregnancy occurred in five rabbits, and four of them had live litters. Hormones levels were normal in all animals. Transplanted ovaries were surrounded by connective tissue, they were well vascularized and contained follicles in different stages of development. Conclusions: Rabbits submitted to allogeneic ovarian transplantation without vascular pedicle and immunosupressed by cyclosporine maintain fertility and female hormone function.
\end{abstract}

Key Words: Ovary; Transplantation; Ovariectomy; Pregnancy; Rabbits; Cyclosporine; Fertilization.

\section{REFERÊNCIAS}

1. Von Theobald P, Roffé JL, Berrocal J, et al. Autotransplantation ovarienne hétérotopique chez la femme. Presse Med, 1987, 6(25):1239-1241,

2. Von Eye Corleta H, Corleta O, Capp E, et al. Subcutaneous autologous ovarian transplantation in Wistar rats maintains hormone secretion. Fertil Steril,1998, 70(1):16-19.
3. Adonakis GL, Paraskevaidis E, Tsiga S, et al. - A combined approach for the early detection of ovarian cancer in asymptomatic women. Eur J Obstet Gynecol Reprod Biol, 1996, 65(2):221-225.

4. Speroff T, Dawson NV, Speroff L, et al. - A risk-benefit analysis of elective bilateral oophorectomy: effect of changes in complicance with estrogen therapy on outcome. Am J Obstet Gynecol, 1991, 164(1 pt 1):165174. 
5. Stiff PJ, Bayer R, Kerger C, et al. - High-dose chemotherapy with autologous transplantation for persistent/relapsed ovarian cancer: a multivariate analysis of survival for 100 consecutively treted patients. J Clin Oncol, 1997, 15(4):1309-1317.

6. Davis SR, Burger HG - A clinical review 82: androgens and postmenopausal woman. J Clin Endocrinol Metab, 1996, 81(8):2759-2763.

7. Wallace WH, Shalet SM, Hendry JH, et al. - Ovarian failure following abdominal irradiation in childhood: the radiosensitivity of the human oocyte. Br J Radiol, 1989, 62(743):995-998.

8. Cornier E, Sibella P, Chatelet F - Etudes histologiques et devenir fonctionnel des greffes de trompe et d'ovaire chez la rate (isogreffes et allogreffes traitées par cycloposrine A). J Gynecol Obstet Biol Reprod, 1985, 14(5):567-573.

9. Ingulli E, González R, Rajpoot D, et al. - Long-term outcome of one haploidentical live related donor transplantation in children. Child Nephrol Urol, 1989, 9(6):312-318.

10. Seethalakshmi L, Flores C, Carboni AA, et al. Cyclosporine: its effects on testicular function and fertility in the prepubertal rat. J Androl, 1990, 11(1):17-24.

11. Sikka SC, Bhasin S, Coy DC, et al. - Effects of cyclosporine on the hypothalamic-pituitarygonadal axis in the male rat: mechanism of action. Endocrinology, 1988, 123(2):1069-1074.

12. Cooper JE - Ethics and laboratory animals. Vet Rec, 1985, 116(22):594-595.

13. Petroianu A - Pesquisa experimental. In Petroianu A (ed) - Ética, moral e deontologia médicas. Rio de Janeiro. Guanabara Koogan, 2000, pp.185-190.

14. Weissman A, Gotlieb L, Colgan T, et al. - Preliminary experience with subcutaneous human ovarian cortex transplantation in the NOD-SCID mouse. Biol Reprod, 1999, 60(6):1462-1467.

15. Green CJ, Simpkin S, Grimaldi G, et al. - Pregnancy after autografting and allografting vascularized ovaries and en bloc vascularized ovaries with adnexa in rabbits. $\mathrm{Br}$ J Obstet Gynaecol, 1982, 89(8):645-651.

16. Candy CJ, Wood MJ, Whittingham DG - Follicular development in cryopreserved marmoset ovarian tissue after transplantation. Hum Reprod, 1995, 10(9):2334-2338.
17. Gunasena KT,Villines PM, Critser ES, et al. - Live births after autologous transplant of cryopreserved mouse ovaries. Hum Reprod, 1997, 12(1):101-106.

18. Parks JE, Ruffing NA - Factors affecting low temperature survival of mammalian oocytes. Theriogenology, 1992, 37(1):59-72.

19. Trounson A, Bongso A - Fertilization and development in humans. Curr Top Dev Biol, 1996, 32, 59-101.

20. Baird DT, Webb R, Campbell BK, et al. - Long-term ovarian function in sheep after ovariectomy and transplantation of autografts stored at $-196^{\circ} \mathrm{C}$. Endocrinology, 1999, 140(1):462-471.

21. Callejo J, Jáuregui MT, Valls C, et al. - Heterotopic ovarian transplantation without vascular pedicle in syngeneic Lewis rats: six month control of estradiol and follicle-stimulating hormone concentrations after intraperitoneal and subcutaneous implants. Fertil Steril, 1999, 72(3):513-517.

22. Harrison FA, Chambers SG, Green EA Autotransplantation of the ovary to the neck in the sow: normal cyclic activity and plasma hormone leves [proceedings]. J Endocrinol, 1979, 83(1):46P.

23. Namba Y, Yamamoto M, Atrishima K, et al. - Suppressive effect of perinatal testes on the differentiation of fetal ovaries transplanted into adult males in the rat. J Anat, 1997, 191(1 pt 1):31-38.

24. Nisolle M, Casanas-Roux F, Qu J, et al. - Histologic and ultrastructural evaluation of fresh and frozenthawed human ovarian xenografts in nude mice. Fertil Steril, 2000, 74(1):122-129.

25. Esquifino AI, Moreno ML, Agrasal C, et al. - Effects of cyclosporine on ovarian function in shamoperated and pituitary-grafted young female rats. Proc Soc Exp Biol Med, 1995, 208(4):397-403.

Endereço para correspondência

Prof. Andy Petroianu

Av. Afonso Pena, 1626 - Apto 1901

30130-005, Belo Horizonte, MG.

FONE(FAX): (31) 3274-7744 